\title{
АКТУАЛЬНОСТЬ ПРОФИЛАКТИЧЕСКОЙ РАБОТЫ ПЕДАГОГА-ПСИХОЛОГА И СОЦИАЛЬНОГО ПЕДАГОГА ПО СНИЖЕНИЮ ПОКАЗАТЕЛЕЙ ПРЕДДЕВИАНТНОГО ПОВЕДЕНИЯ В СТАРШЕМ ДОШКОЛЬНОМ ВОЗРАСТЕ В ОБРАЗОВАТЕЛЬНОЙ ОРГАНИЗАЦИИ
}

\author{
Павлова Оксана Викторовна \\ магистрант \\ Нижневартовский государственный университет \\ Научный руководитель: Романко Оксана Анатольевна \\ доцент, кандидат психологических наук, доцент \\ Нижневартовский государственный университет
}

Аннотация: В статье рассматривается актуальность профилактической работы педагога-психолога и социального педагога по снижению показателей преддевиантного поведения в старшем дошкольном возрасте в образовательной организации.

Ключевые слова: девиантное поведение, преддевиантное поведение, копинг стратегии, психолого-педагогическая профилактика.

Дискуссии на присвоение норм и ценностей у подрастающего поколения, принятых в обществе, включая моральные и нравственные ценности, в системе отечественного образования не теряют остроты. Родители, преподаватели не на шутку встревожены девиантным поведением молодёжи, в то время как чиновники министерства образования продолжают уверять, что всё под контролем. Высокий уровень невротизации общества оказывает негативное влияние на психологическое самочувствие, эмоциональное благополучие, здоровье и даже жизнь ребенка. Исследование проблемы преддевиантного поведения в старшем дошкольном возрасте открывает возможности для более глубокого анализа психологических закономерностей и механизмов регуляции поведения человека, формирования его внутреннего мира, подтверждает социальную обусловленность психики и образа жизни индивида, так как в социальном обществе с каждым годом увеличивается рост детей с отклоняющимся поведением, начиная с дошкольного возраста. В исследованиях М.А. Ковальчук, В.Г. Буртоновой, А.В. Мудрика и др. выдвинута проблема изучения девиантного поведения и социально- 
психологической профилактики преддевиантного поведения в дошкольном возрасте $[2,9,11]$.

А.В. Мудрик, девиантное поведение в самом широком смысле слова определяет как «поведение, отклоняющееся от общепринятых, социально одобряемых, широко распространенных, устоявшихся норм в определенных сообществах в определенный период их развития» [11].

С.В. Шепелева рассматривает преддевиантное поведение в дошкольном возрасте как импульсивно-ситуативное проявление парциальных особенностей отклоняющегося поведения, обусловленное ограничивающими (нормативными) ситуационными условиями микросреды и оказывающее деструктивное влияние, на процессы межличностных отношений и личностной социализации ребенка [17].

Поскольку преддевиантное поведение в старшем дошкольном возрасте является антисоциальным поведением личности, а копинг стратегии остаются недостаточно исследованными и их эффективность до сих пор не изучена, проблема исследования заключается в разрешении вопроса профилактики преддевиантного поведения в старшем дошкольном возрасте посредством применения различных копинг стратегий, так как девиантное поведение можно скорректировать с помощью выработки (формирования) копинг стратегий. Проблемами психологической профилактики и коррекции детей и подростков разрабатывалась в трудах ряда отечественных и зарубежных учёных: Г.В. Бурменской, Р. Бернса, И.П. Воропаевой, Г.Ф. Кумариной, О.А. Карабановой, В.С. Мухиной, М. Раттера, Дж. Рассела, В.В. Столиной, Ю.А. Клейберга, Е.В. Змановской, В.Ф. Шевчука, Е.В. Кучинской, М.В. Маркеевой, В.В. Стрельцовой и др.

Психолого-педагогическая профилактика - это «система предупредительных мероприятий, связанных с устранением внешних причин, факторов и условий, вызывающих те или иные недостатки в развитии ребёнка, а также направленных на сохранение и укрепление благоприятного состояния ребёнка» [2].

В исследованиях М.И. Голикова, О.А. Кирсанова показано, что основными звеньями профилактики девиантного поведения являются:

1) общая ранняя профилактика отклонений в поведении детей, включающая в себя общие педагогические, медицинские, социальные формы работы с детьми и подростками, направленные на совершенствование, повышение эффективности учебно-воспитательной, оздоровительной работы; 
2) ранняя специальная профилактика, включающая в себя индивидуальную консультацию и другие виды специализированной помощи детям, родителям, учителям по преодолению начальных форм отклонений в поведении, предупреждению и преодолению социально-педагогической запущенности, дезадаптации, по организации оздоровительной и других форм работы;

3) вторичная специальная профилактика, включающая в себя меры преодоления социально-психологической дезадаптации, отклонений в нравственном, социальном, психическом и физическом развитии, поведении детей и подростков, проведение коррекционной, реабилитационной и реадаптационной работы с ними в общих учебных и специальных воспитательных учреждениях, переориентации деятельности различных групп и объединений несовершеннолетних асоциальной и криминогенной направленности [3].

З.К. Давлетбаева и Ф.Ф. Гумерова считают, что условием успешной профилактической работы считают учёт её основных принципов: комплексность (организация воздействия на различных уровнях социального пространства, семьи и личности); последовательность; своевременность; адресность, дифференцированность (учет возрастных, половых и социальных характеристик); массовость (приоритет групповых форм работы); позитивность информации; минимизация негативных последствий; личная заинтересованность и ответственность участников; максимальная активность личности; устремленность в будущее (оценка последствий поведения, актуализация позитивных ценностей и целей, планирование будущего без девиантного поведения) [4].

Е.В. Змановская к основным направлениям (стратегическим целям) работы по профилактике девиантных форм поведения у несовершеннолетних относит следующие:

- стабилизация психоэмоционального состояния (обучение навыкам вербализации чувства, преодоления негативных эмоциональных состояний);

- обучение навыкам саморегуляции, изменение стереотипов эмоционального реагирования;

- развитие внутренних показателей самооценки и повышение уровня рефлексии (формирование позитивного самовосприятия и самоотношения);

- актуализация личностных ресурсов, реализация творческого потенциала; 
- формирование коммуникативных умений и навыков;

- формирование навыков совладающего и ассертивного поведения [6].

Для организации профилактической работы по снижению девиантного поведения дошкольников педагог-психолог и социальный педагог в детском образовательном учреждении определяют нарушения процесса социализации ребёнка, который зависим от внешних и внутренних факторов. При этом они должны руководствоваться Федеральным государственным образовательным стандартом дошкольного образования (далее - ФГОС ДО), т.е. нормативным государственным документом, определяющим целевые ориентиры и требования к дошкольному образованию, воспитанию дошкольников в требуемых поведенческих нормах [13].

Поставленные в стандарте задачи образования создают психологопедагогические предпосылки для профилактики преддевиантного поведения дошкольников, поскольку через реализацию задач предусматривается охрана и укрепление физического и психического здоровья детей, сохранение их эмоционального благополучия, обеспечение в дошкольных учреждениях равных возможностей для полноценного развития каждого ребёнка. Воспитание и обучение объединяется в целостный процесс на основе духовно-нравственных и социокультурных ценностей, принятых в обществе правил и норм поведения. У детей формируется общая культура личности, ценности здорового образа жизни, развиваются социальные, нравственные, эстетические, интеллектуальные и физические качества, самостоятельность, инициативность и ответственность ребенка [13].

Авторы Комплексной образовательной программы дошкольного образования «Детство» [14] связывают шестой год жизни ребёнка с его вхождением в мир социальных отношений. Основными задачами образовательной деятельности «Социально-коммуникативное развитие» они называют:

- воспитание культуры поведения и общения, привычки следовать правилам культуры, быть вежливым по отношению к людям, сдерживать непосредственные эмоциональные побуждения, если они приносят неудобство окружающим;

- воспитание доброжелательного отношения к людям, уважение к старшим, дружеские взаимоотношения со сверстниками, заботливое отношение к малышам; 
- развитие положительной самооценки, уверенности в себе, чувство собственного достоинства, желание следовать социально одобряемым нормам поведения, осознание роста своих возможностей и стремление к новым достижениям [14].

В программе выделены также результаты образовательной деятельности - достижения ребенка в образовательной области «Социальнокоммуникативное развитие» и то, что должно вызывать озабоченность, и требует совместных усилий педагогов и родителей. Например, если ребенок имеет представления о правилах культуры поведения и общения, но часто их нарушает, нуждается в постоянном контроле взрослого; или конфликтует со сверстниками, не хочет прислушиваться к мнению партнеров по игре, отказывается от выполнения общих правил, если они препятствуют его интересам и возможности получить выигрыш; жалуется на нарушение правил поведения другими детьми, свои промахи связывает только с виной других детей [14].

По мнению К.М. Гуревич и Е.М. Борисовой, старший дошкольный возраст играет особую роль в развитии ребенка: в этот период жизни начинают формироваться новые психологические механизмы деятельности и поведения. Развитие детей 5-7 лет происходит успешно при условии удовлетворения в образовательном процессе ведущих социальных потребностей дошкольников:

- потребность в положительных эмоциональных контактах с окружающими (воспитателем, детьми), в любви и доброжелательности;

- потребность в активном познании и информационном обмене;

- потребность в самостоятельности и разнообразной деятельности по интересам;

- потребность в активном общении и сотрудничестве со взрослыми и сверстниками;

- потребность в самоутверждении, самореализации и признании своих достижений со стороны взрослых и сверстников [15].

Предупреждение проявления показателей преддевиантного поведения в старшем дошкольном возрасте будет продуктивным если:

- своевременно проводить психолого-педагогическое диагностирование показателей преддевиантного поведения в старшем дошкольном возрасте и диагностику актуального уровня развития ребёнка (А.Б. Фомина) [16]; 
- разрабатывать и осуществлять профилактические программы, с целью управления процессом социализации детей старшего дошкольного возраста (И.Ж. Калашников) [8];

- проводить просвещение и подготовку педагогов по вопросу коррекционно-развивающего обучения, осуществления здоровьесберегательных технологий (Н.В. Андрущенко) [1].

В исследованиях Е. А. Казаевой и О. Г. Шабардиной [7] условиями методики педагогической поддержки детей старшего дошкольного возраста с отклоняющимся поведением в образовательном пространстве ДОУ выступают:

- применение преддевиантной диагностики и профилактики отклоняющегося поведения дошкольников (модифицированной программы диагностического обеспечения профилактики отклоняющегося поведения старших дошкольников);

- культивирование общечеловеческих ценностей и гуманных отношений в детском коллективе. Они лежат в основе формирования у старших дошкольников структуры жизненных ценностей (интенсивное освоения ребенком этических правил, моральных норм и нравственных чувств личности на основе детского коллектива); формирование своеобразной среды для освоения социокультурного опыта и нравственных привычек поведения (вежливого общения, развития способностей, успешной познавательной и творческой деятельности, познания себя и др.);

- организация партисипативных отношений субъектов образовательной среды дошкольного образовательного учреждения, которое предусматривает использование группового и личностного потенциала ребенка, вовлеченность при выполнении совместной деятельности и уважительность в принятии совместных решений.

Обучение старших дошкольников технике выражения эмоций включает в себя: формирование позитивного эмоционального отношения к сверстникам; снятие страхов, тревоги; развитие элементов творческого воображения, придумывание различных способов самовыражения на основе правильного восприятия оттенков эмоционального состояния партнера (радости, печали, интереса, удивления, обиды, гордости, гнева, страха и др.) (Л.А. Венгер, М.А. Камбурова, И.А. Пазухина, М.А. Толстикова, Г.А. Цукерман, М.И. Чистякова и др.). 
Формами профилактической работы педагога-психолога по снижению показателей девиантного поведения в ДОУ являются: организация социальной среды; информирование; активное социальное обучение социально-важным навыкам; организация деятельности, альтернативной девиантному поведению; активизация личностных ресурсов, минимизация негативных последствий.

Как считает А. М. Печенюк, в целях предупреждения преддевиантного и девиантного поведения используются различные социально-психологические методы: информирование, групповые дискуссии, тренинговые упражнения, ролевые игры, моделирование эффективного социального поведения, психотерапевтические методики. В настоящее время в рамках реализации тех или иных форм организации профилактической деятельности используются следующие основные группы методов воздействия на девиантное поведение личности: стимулирование мотивации изменения поведения, коррекции эмоциональных нарушений, методы саморегуляции, когнитивного переструктурирования, угасания нежелательного поведения, формирования позитивного поведения [12].

Специфической особенностью методики педагогической поддержки детей старшего дошкольного возраста с отклоняющимся поведением, по мнению Е.А. Казаевой и О.Г. Шабардиной, выступает совокупность партисипативных методов, основанных на знании и учете педагогической ценности и целевой направленности следующих групп методов:

a) методов развития самосознания старших дошкольников (ритмопластика, детский театр, ситуационно-ролевые игры, этические беседы, психогимнастика, взаимообучение);

б) методов стимулирования поведения и деятельности (создание ситуации успеха, познавательные игры, обучающие дискуссии, рейтинг, поручение, убеждение, конкурсы, метод примера, поощрение, коррекция поведения);

в) методов развития творческого мышления (метод ситуационного анализа, игровое проектирование, взаимное компромиссное согласование, метод вопросов и ответов, групповое консультирование, развивающие игры);

г) методов педагогической поддержки старших дошкольников с отклоняющимся поведением: методов контроля (наблюдение, учет и анализ, изучение результатов продуктивной деятельности, портфолио, взаимоконтроль, взаимооценка) [7]. 
В разных видах психопрофилактической работы могут использоваться схожие формы и методы.

Копинг-стратегии необходимы в личностном развитии. Цель ознакомления с копинг-стратегиями: выбор индивидуального способа совладения с затруднительной ситуацией в соответствии с ее значимостью в жизни и личностно-средовыми ресурсами, определяющим поведение данного человека. При этом значимость применения копинг-стратегии это устранение или уменьшение силы воздействия неприятной ситуации на дошкольника. Таким образом, копинг-стратегия предназначена на разрешение проблемы.

Дошкольников необходимо научить следующим копинг-стратегиям:

- «стратегия избегание». Данная стратегия может быть адекватной, так и неадекватной, так как предназначена для разрешения стресса с низкими личностно-средовыми ресурсами. Она предполагает избегание неуспеха, стремление остаться внутри меняющейся социальной ситуации, пассивно принимая её и приспосабливаясь к ней. Это невосприятие окружающей среды как возможного источника ресурсов для принятия решения при возникновении проблем;

- «разрешение проблем» определяется степенью осознания собственной поведенческой ситуативной эффективности. При использовании данной стратегии необходимы прямые действия (обсуждение ситуации, изучение ситуации);

- «поиск социальной поддержки». Важным применением данной копингстратегии является изменение социально-поддерживающего процесса. Социально-поддерживающий процесс включает в себя 3 компонента: социальные сети, субъективное восприятие социальной поддержки и копингстратегию «поиск социальной поддержки». Доброжелательная помощь, семейная, дружеская поддержка значимыми другими крайне важна для людей, оказавшихся в стрессовой ситуации. Важен средовой ресурс, выраженный в восприятии дружеской поддержки.

По способу организации работы выделяют следующие формы психопрофилактики: индивидуальная, семейная, групповая работа. Так, например, Е.К. Лютова и Г.Б. Монина описывают работу педагогапсихолога и социального педагога с семьей. Взрослым необходимо учитывать и поддерживать проявления индивидуальности в ребенке. Своим поведением воспитатель показывает примеры доброго, заботливого отношения к людям, он побуждает ребят замечать состояние сверстника 
(обижен, огорчен, скучает) и проявлять сочувствие, готовность помочь. Он привлекает внимание детей к внешним признакам выражения эмоционального и физического состояния людей, учит прочитывать эмоции, побуждает детей замечать эмоциональное состояние окружающих людей и сверстников (обижены, огорчены, скучают) и проявлять сочувствие и готовность помочь [10].

А.Н. Евдокимов отмечает, что на седьмом году жизни нередко возникают сложности в поведении и общении ребенка со взрослыми. Старшие дошкольники перестают быть наивными и непосредственными, как раньше, становятся менее понятными для окружающих. Ребенок порой ведет себя вызывающе, манерничает, кого-то изображает, кому-то подражает. Он как бы примеряет на себя разные модели поведения, заявляя взрослому о своей индивидуальности, о своем праве быть таким, каким он хочет. Психологи связывают это с проявлением кризиса семи лет [5].

Появление подобных особенностей в поведении должно стать для близких взрослых сигналом к перемене стиля общения с ребенком. Надо относиться к нему с большим вниманием, уважением, доверием, активно поддерживать стремление к самостоятельности. Старшие дошкольники очень чувствительны к оценкам взрослых. Они остро переживают, если взрослый выражает сомнение в их самостоятельности, ограничивает свободу. Необходимо поддерживать в детях ощущение своего взросления, вселять уверенность в своих силах. Развитию самостоятельности способствует освоение детьми универсальных умений: поставить цель (или принять ее от воспитателя), обдумать путь к ее достижению, осуществить свой замысел, оценить полученный результат с позиции цели. При этом воспитатель использует средства, помогающие дошкольникам планомерно и самостоятельно осуществлять свой замысел: опорные схемы, наглядные модели, пооперационные карты.

Профилактика преддевиантного поведения проводится с детьми, не имеющими отклонений в поведении. Эти дети либо входят в группу нормоориентированных детей, у которых риск возникновения девиантного поведения отсутствует, либо составляют группу риска девиантного поведения, где девиантное поведение еще не сформировалось, но риск его появления уже возник. Для психологической службы ДОУ, педагогов и родителей в этот период нужно обратить особое внимание на обучение и развитие данной группы детей [12]. 
Таким образом, в системе управляемой и стихийной социализации ребёнка дошкольного возраста профилактика преддевиантного поведения должна занимать достойное место в работе педагога-психолога и социального педагога в ДОУ. В ходе профилактической работы педагог-психолог применяет комплекс психологических мероприятий, направленных на предупреждение и устранение психологических причин и факторов риска девиантного поведения посредством развития личностных свойств, охрану эмоционального благополучия и обеспечение успешности социализации дошкольника.

\section{Список литературы}

1. Андрущенко, Н.В. Характеристика уровней воспитанности здоровьесберегающего поведения детей старшего дошкольного возраста // Научно-методический электронный журнал «Концепт». - 2016., № 12.[Электронный ресурс]. - Режим доступа: http://e-koncept.ru/2016/16272.htm. (дата обращения: 21.01.2020).

2. Буртонова, И.Б. Социально-педагогические стратегии профилактики девиантного поведения подростков в условиях общеобразовательной школы // Вестник Бурятского государственного университета. - 2015. - Вып. 3. - С. 48-54.

3. Голикова, М.И. Организация работы с трудными детьми / М.И. Голикова, О.А. Кирсанова // Кл. рук. - 1999. - № 1. - С. 27-39.

4. Давлетбаева, 3.К., Гумерова, Ф.Ф. Предасоциальные паттерны поведения детей // Вестник Костромского государственного университета. Серия: Педагогика. Психология. Социокинетика. 2015. - №4. - С. 72-76.

5. Евдокимов, А.Н. Психолого-педагогическая поддержка личности дезадаптивного ребёнка в дошкольном образовательном учреждении // Перспективы науки. - 2011. - № 17. - С. 24-29.

6. Змановская, Е.В. Девиантология: (Психология отклоняющегося поведения): Учеб. пособие для вузов / Е.В. Змановская. - М.: Академия, 2013. $-287 \mathrm{c}$.

7. Казаева, Е. А., Шабардина, О. Г. Методико-технологическое обеспечение педагогической поддержки детей старшего дошкольного возраста с отклоняющимся поведением // Педагогическое образование в России. - 2014., №10. - С. 105-113. 
8. Калашников, И.Ж. Возрастной подход в организации первичной профилактики девиантного поведения // Вестник Уральского института экономики, управления и права - 2013, С. 70 - 73.

9. Ковальчук, М.А., Тарханова, И.Ю. Девиантное поведение. Профилактика, коррекция, реабилитация / М. А. Ковальчук, И. Ю. Тарханова. - М.: Владос-Пресс, КДУ, 2013. - 286 с.

10. Лютова Е.К., Монина Г.Б. Шпаргалка для родителей: Психокоррекционная работа с гиперактивными, агрессивными, тревожными и аутичными детьми. - СПб.: Речь; М.: Сфера, 2010. - 136с. ил.

11. Мудрик, А.В. Введение в социальную педагогику / А.В. Мудрик - М.: Институт практической психологии, 2014.

12. Печенюк, А.M. Теоретические основы гуманистическиориентированного процесса профилактики девиантного поведения несовершеннолетних: Дис... д-ра пед. наук /А. М. Печенюк. - Хабаровск, 2000. $-421 \mathrm{c}$.

13. Приказ Министерства образования и науки Российской Федерации от 17.10.2013г. №1155 «Об утверждении Федерального государственного образовательного стандарта дошкольного образования» [Электронный pecypc]. - Режим доступа: https://минобрнауки.рф/документы/6261

14. Программа Детство: Примерная образовательная программа дошкольного образования / Т.И. Бабаева, А.Г. Гогоберидзе, 3.А. Михайлова, О.В. Солнцева и др. - СПб.: ООО «Издательство «Детство-Пресс», Издательство РГПУ им. А.И. Герцена, 2016. - 528 с.

15. Психологическая диагностика: Учебное пособие /Под ред. К.М. Гуревича и Е.М. Борисовой. - М.: Изд-во УРАО, 1997. - 304 с.

16. Ранняя профилактика девиантного поведения детей и подростков: Интегративная социально-педагогическая деятельность учреждений дополнительного образования и общеобразовательной школы: Учеб. пособие /под ред. А. Б. Фоминой. - М.: Педагогическое общество России, 2013. - 128c.

17. Шепелева, С.В. Психология преддевиантного поведения. /С.В. Шепелева - Кострома: КГУ им. Н. А. Некрасова, 2018. - 168 с. 